\title{
Engineering graphics in a community-college setting: Challenges and opportunities
}

\section{Dr. Hannah Dawes Budinoff, Pima Community College}

Hannah D. Budinoff is a researcher interested in additive manufacturing, geometric manufacturability analysis, design for manufacturing, and engineering education. She received her BS in mechanical engineering from the University of Arizona and recently completed her $\mathrm{PhD}$ in mechanical engineering at the University of California, Berkeley, where she was awarded an NSF Graduate Research Fellowship. Dr. Budinoff teaches CAD classes in her role as Instructional Faculty at Pima Community College. 


\title{
Engineering graphics in a community-college setting: Challenges and opportunities
}

\begin{abstract}
This evidence-based practice paper describes a study of the efficacy of several engineering education pedagogy practices in an engineering graphics course at a large community college in the southwestern US. The student population at community colleges is typically diverse and has a larger proportion of non-traditional students relative to four-year institutions. Most studies of engineering graphics research are conducted at four-year institutions, but results derived from the more diverse student populations at community colleges could help develop more general strategies to improve retention of underrepresented groups in engineering. In this paper, we survey some of the unique demographic and social challenges of community college students and assess the following pedagogical strategies derived from previous literature: lab activities, active learning, and improving spatial visualization ability. Lab activities and content that encourage active learning have been previously cited as effective strategies for engaging nontraditional students. Spatial visualization ability has been shown to impact learning outcomes in engineering graphics courses, and activities like sketching have been shown to help students with low spatial visualization. This study focuses on an introductory engineering graphics course that teaches modeling and assembly and drawing creation in SolidWorks, a 3D computer-aideddesign software. We discuss the impact of lab time, active learning activities, and sketching activities on student's self-efficacy and perceived learning, as well as connections between spatial visualization ability and learning outcomes. Students reported a large increase in their 3Dmodeling self-efficacy over the semester and agreed that working on CAD during lab time and following along with instructor demos were helpful to their learning. In an attempt to improve spatial visualization ability of the students, sketching components were included during the course. The average spatial visualization skills of the students improved over the semester, but students had mixed agreement about whether the sketching activities were helpful for learning course material. Our results are compared to previously reported findings from four-year institutions and other community colleges, when available. We highlight promising strategies to promote learning and confidence for diverse student populations learning engineering graphics, which could potentially improve retention at other community colleges and four-year institutions.
\end{abstract}

\section{Introduction}

In an effort to increase access to university education for low- and middle-class families, at least 17 states have begun offering opportunities to attend two-year colleges tuition free [1]. Already, roughly $50 \%$ of engineers in the workforce with a terminal bachelor's degree have taken classes at a two-year college as part of earning their degree [1], and this number could continue to grow as states try to increase access to community college courses. Articulated agreements between community colleges and universities enable students to take their fundamental engineering courses at a community college and transfer the credits to a university. These partnerships have many advantages: students can access more mentoring and support due to smaller class sizes; tuition costs are often lower for students; and it is possible to recruit engineering undergraduates from a more diverse student population [2]. 
As an example, the largest community colleges in Arizona tend to have a higher population of students from non-traditional backgrounds and under-represented groups. The two largest universities in Arizona, the University of Arizona and Arizona State University, have relatively diverse populations. At the University of Arizona and Arizona State University, 35\% and $40 \%$ of engineering undergraduates are minority students, respectively [3],[4]. Pima Community College and Maricopa Community College, two large, multi-campus community colleges in the same metropolitan areas as the University of Arizona and Arizona State University, respectively, are more diverse than their four-year counterparts. Pima Community College is $55 \%$ minority and Maricopa Community College is 57\% minority [5],[6]. Many of the students at these community colleges are also non-traditional students in that they have substantial work experience or may be working a full-time job while taking classes.

While creating a pipeline for community college students to transfer to a university is an exciting opportunity to increase access to higher education, there are some institutional and pedagogical challenges. A recent survey of 2,100 community college students nationwide found that work and paying expenses were the top two challenges to academic success that students reported having to overcome [7]. Non-traditional students often have different motivation for enrolling in engineering courses than traditional students, and also have different gaps in knowledge [8]. We need to understand how to support these diverse students in engineering courses, both at the community college level and once they transfer to a university.

Our focus in this study is on how to best support community college students in engineering graphics courses, specifically 3D CAD courses, which are often required early in the engineering curriculum. Spatial visualization ability, which is the ability to mentally operate (e.g., rotate, mirror) on 3D shapes, has been found to be correlated to success in 2D engineering graphics courses and can also impact success in 3D CAD courses [9],[10]. Students from different race and ethnic backgrounds and different socioeconomic status have, on average, differing levels of spatial visualization ability [11],[12],[13],[14],[15]. To promote equitable outcomes for a diverse student population, it is therefore necessary to support students by helping them raise their spatial visualization ability.

Although there is a large body of research studying spatial visualization ability and its impact in engineering graphics courses, there is less research focused on community colleges. One study that conducted pre- and post-PSVT:R exams found that taking a CAD course at a community college did not result in statistically significant improvements in spatial visualization [16]. However, other researchers have reported success stories of how improving spatial visualization ability leads to improved outcomes (e.g., retention, course grades). Scribner and Anderson recommend employing a wide variety of teaching methods to help students with different learning styles improve their spatial visualization at the community-college level [17]. Grimes and Daniel report success at improving spatial visualization ability of community college students by employing training materials developed by Sorby in a required orientation course [18]. Preliminary results of a large, multi-institution NSF-funded deployment of spatial-skills training (Spatial Skills Instruction Impacts Technology Students, or SKIITS) indicate that such training improves spatial skills and course grades of community college students [19]. 
In lieu of a new course to support spatial visualization, this paper seeks to identify strategies that can be employed in existing CAD courses to support student success. There is a need for better understanding of what specific strategies work best at community colleges for improving spatial visualization and helping students achieve successful outcomes in CAD courses. These strategies could likely also help support students from non-traditional backgrounds and under-represented groups at a university setting as well. In this study, we report on observations regarding students' spatial visualization, self-efficacy, barriers to success, and preferences towards different learning methods, such as lab activities and sketching.

\section{Methods}

This study was conducted at Pima Community College (PCC), a large community college in Tucson, Arizona, in the fall semester of 2019. The study was conducted in an introductory 3D CAD course, which focuses on modeling parts in SolidWorks. The majority (69\%) of the students surveyed from this class were enrolled as full-time students (i.e., taking 12 or more credits). Most of the class (76.9\%) had taken 30 or less units at the community college before the start of the fall semester, which corresponds roughly to freshman or sophomore status. Most students were enrolled in an associates of applied science degree program, focused on CAD.

To assess the students' spatial visualization ability, the 30 item Purdue Spatial Visualization Test: Rotations (PSVT:R) [20] was administered on paper with a time limit of 20 minutes. The pre-test was administered the first day of class, and the post-test was administered in the last week of class, with a span of about 15 weeks between testing. Students were given approximately three assignments throughout the semester that required them to sketch orthographic projections and isometric views of objects. These assignments were designed to help improve spatial visualization ability. However, the class was generally focused on 3D modeling skills and SolidWorks operation, and not on spatial visualization ability.

A survey was also administered to assess self-efficacy and to ask the students about how helpful they found the different learning activities in the course. We measured self-efficacy regarding 3D graphics topics using the three-dimensional modeling self-efficacy scale described by Densen and Kelly [21]. We will refer to this scale as the 3DM-SES in this paper. Agreement on each item of the nine items of this survey is measured using a seven-point Likert-type scale from "strongly disagree" (which was scored with a value of 1) to "strongly agree" (which was scored with a value of 7). The questions used in the self-efficacy scale are listed in Table 1. The 3DMSES was administered to students at the end of the semester. Students were asked to answer each of the nine 3DM-SES questions twice: once, from their perspective at the start of the semester (e.g., "I felt that I was good at visualization and manipulating 3-D objects in space"); and again, from their current perspective after taking the course. These responses are referred to as "before" and "after" responses on the 3DM-SES. 
Table 1. Students completed the 3DM-SES [19], a short survey with the following questions

\begin{tabular}{ll} 
Question & Question text \\
\hline 1 & I feel that I am good at visualizing and manipulating 3-D objects in space. \\
2 & I have confidence in my ability to model 3-D objects using a computer. \\
3 & I am confident enough in my 3-D modeling to help others model 3-D objects. \\
4 & I am good at finding creative ways to model 3D objects. \\
5 & I believe I have the talent to do well in 3-D modeling. \\
6 & I feel comfortable using 3-D modeling software. \\
7 & I feel confident in my ability to create 3-D objects in a variety of ways. \\
8 & I feel I can communicate 3D objects to other peers. \\
9 & I always understand what 3D images are trying to communicate.
\end{tabular}

The portion of the survey regarding learning activities listed six different learning methods employed in the course (lectures, instructor demonstrations of SolidWorks capabilities, working on assignments and activities during class time, sketching activities, class discussions, and completing homework outside of class time). The students were asked to rate how strongly they agreed that each method helped them learn course material on a seven-point Likert-type scale from "strongly disagree" to "strongly agree."

\section{Results and discussion}

Enrollment in this course at the end of the semester was too small to conduct meaningful evaluations of correlations between spatial visualization, performance in the course, and selfefficacy. However, it is noteworthy that many of the students who dropped out of the course or stopped attending after a few weeks had low PSVT:R scores (75\% of students who dropped the course early had scored below 20). This is a similar result to that observed at Tidewater Community College, which reported high dropout rates for students with low spatial visualization ability who did not receive special training [18]. To improve retention, more oneon-one interventions starting immediately in the semester may be needed to prevent students with low spatial visualization from dropping out. Individualized interventions may be especially needed for non-traditional students, whose time and attention is split between work and school.

To compare PSVT:R scores at the start and end of the semester, we only used scores from students who took both the pre- and post-PSVT:R exams. The average score at the start of the semester was $21.00(n=13, S D=5.96)$ and the average score at the end of the semester was 24.69 $(n=13, S D=4.63)$. The increase between these scores was statistically significant according to a Wilcoxon Signed-Rank test $(z=-2.395, p=.0082)$. Three students who started the semester as low visualizers saw large increases ( $\geq 9)$ in their PSVT:R score. These large increases may indicate that the concentrated amount of supervised lab time is beneficial to low visualizers. However, the sample size here is small, and so these results need to be monitored over several semesters. 
The increase reported here between pre- and post-PSVT:R scores is higher in magnitude than what has been observed previously for students enrolled in courses with a focus on 3D CAD (Table 2). The large increase seen here, however, is likely influenced by the fact that our students had lower initial average PSVT:R scores than most other studied colleges and universities.

Table 2. Comparison of average pre- and post-PSVT:R scores for students enrolled in 3D CAD courses

\begin{tabular}{lllll} 
Institution & Pre-PSVT:R & Post-PSVT:R & Change & Source \\
\hline PCC & 21.00 & 24.69 & $+3.69(17.5 \%)$ & \\
NAU & 20.57 & 22.51 & $+1.94(9.4 \%)$ & {$[9]$} \\
Purdue & 23.83 & 25.30 & $+1.47(6.2 \%)$ & {$[22]$} \\
MTU & 22.80 & 23.49 & $+0.69(3.0 \%)$ & {$[23]$} \\
WMU & 22.43 & 24.07 & $+1.64(7.3 \%)$ & {$[24]$}
\end{tabular}

The initial self-efficacy regarding 3D modeling topics varied widely, as evidenced by students' scores on the 3DM-SES, but in general, students' self-efficacy improved by the end of the course. The average score on the 3DM-SES was $3.58(n=13, S D=1.24)$ before taking the course and $5.85(n=13, S D=0.57)$ after taking the course. The increase between these scores is statistically significant according to a Wilcoxon Signed-Rank test $(z=-3.11, p<.001)$. The selfefficacy score at the end of the semester that we observed is similar in value to that reported by Kelly [25] in a study conducted near the end of the semester in a freshman-level CAD course at a large land-grant university, where the average score was $5.54(S D=0.90)$. The similarity between our scores at PCC and scores reported at a university is a promising result, indicating that our students are still able to achieve similar confidence and feelings of competence to university students. 


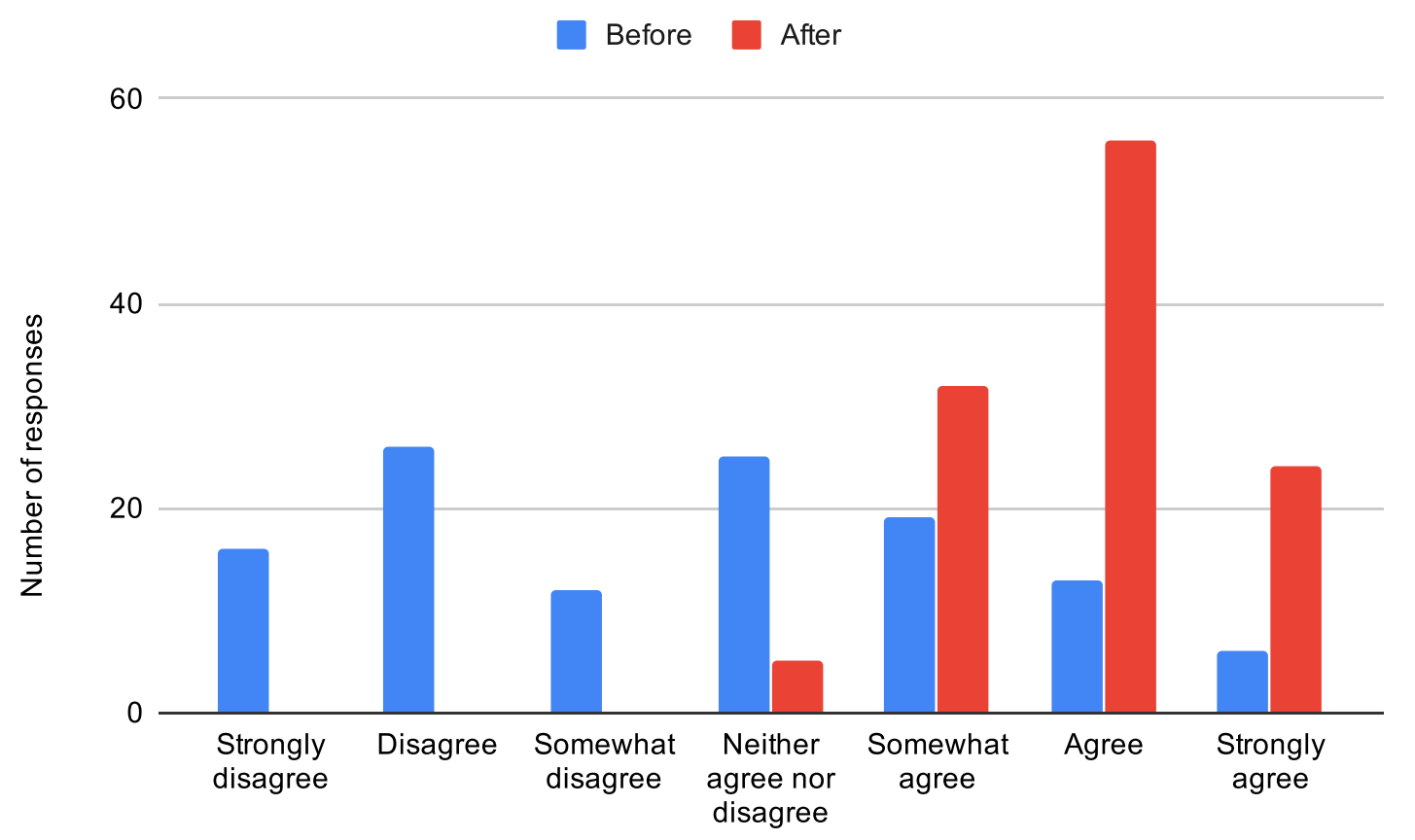

Figure 1. Count of responses on the 3DM-SES before taking course and after taking course (counts are summed for all nine questions and for all respondents).

Student responses indicate that lectures, demos, and working during class time on assignments were the most helpful to their learning (Fig. 2). All surveyed students responded that they agreed or strongly agreed that completing CAD assignments during class time was helpful. The students did not have this same level of agreement on the utility of any of the other learning methods in the survey. This result is consistent with previous findings of Enriquez et al. [26], who found that students at their community college preferred lab activities in an engineering graphics course. Students also generally reported that they agreed that sketching activities, working outside of class, and discussing course content with peers was helpful, but there was generally more mixed agreement about the impact of these three learning methods (Fig. 3). It seems likely that even though sketching was helpful in improving spatial visualization ability, the connection between sketching and building parts in CAD was not clearly emphasized in class, and so students did not fully see its utility. 


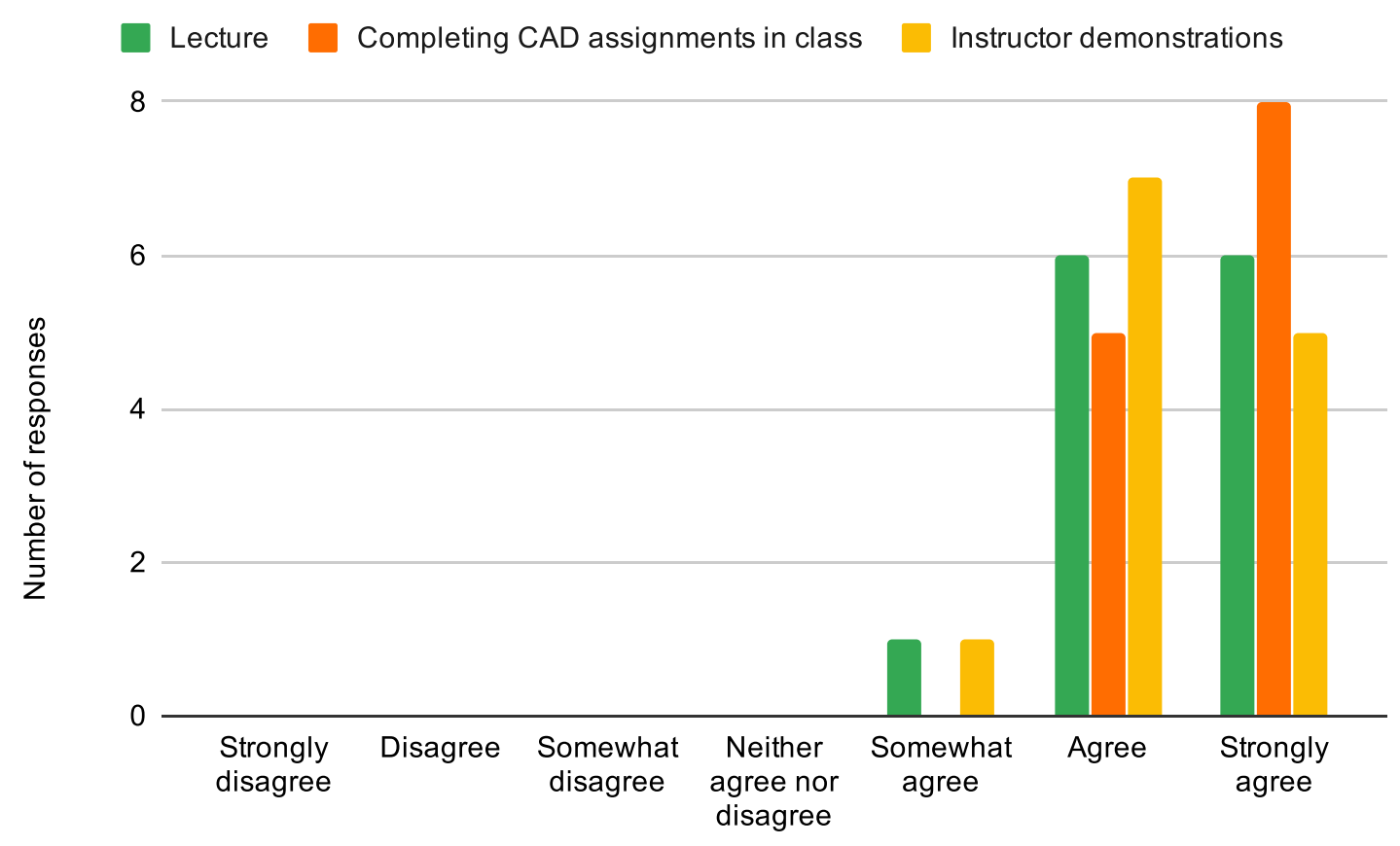

Figure 2. All students agreed that lecture, completing CAD assignments during class time, and instructor demonstrations helped them learn course material.

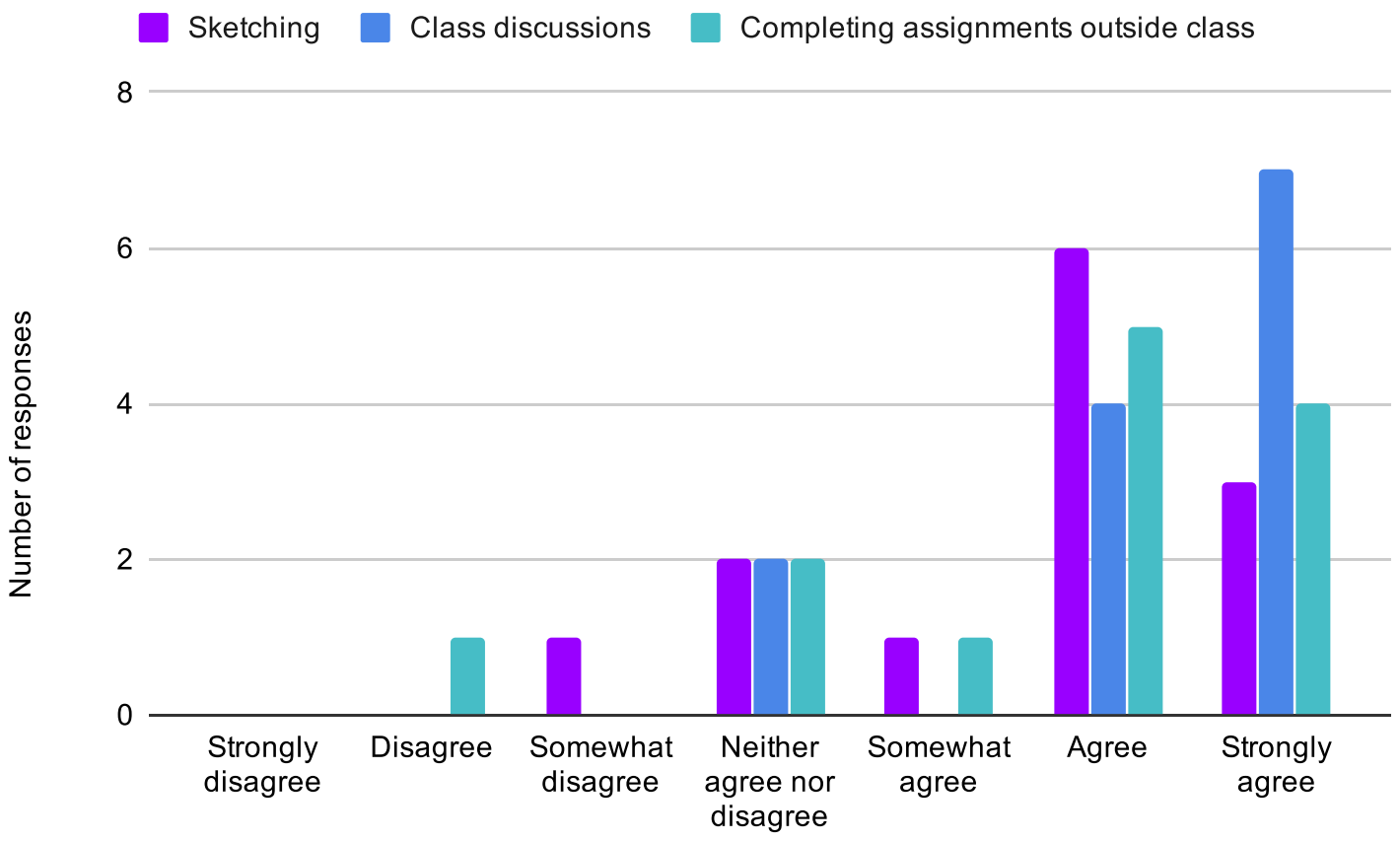

Figure 3. The majority of students agreed that sketching, class discussions, and completing CAD assignments outside of class helped them learn course material.

Students were asked to identify barriers to their full participation and performance in the class. Although spatial visualization has been associated with success in CAD courses [9],[10], spatial 
visualization ability was not cited by students as a barrier to their success. Students were aware that their spatial visualization ability could impact their success because it was discussed during the course, but spatial skills were not mentioned by a single student in response to this portion of the survey. It is possible that the large increase we observed in average spatial visualization ability helped students feel confident in their spatial abilities by the end of the course.

Balancing the demands on their time outside of class was a commonly cited barrier to success. On average, students reported spending 8.3 hours on coursework, including time in class. Since students spent 5.3 hours in the classroom each week, this implies that they spent about 3 hours outside of class on coursework. One student reported, "Finding time to finish homework was the most challenging, but I did." Similar to the results of [7], students identified balancing external employment as a challenge to their academic success. One student responded that their largest obstacle was finding enough time to complete assignments: "I took 15 credits this semester. I don't think I realized how much work that would be. I learned a lot and I wouldn't take it back, but I do regret not having the necessary amount of time to spend on perfecting my assignments." A similar comment from another student said, "Taking a full 15 hour semester and not knowing how hard it would be since its [sic] my first full semester of college since getting out of the military." Throughout the semester, it was observed that many students seemed to struggle with completing assignments outside of class. Completing assignments in class seemed highly preferred by the students.

The survey data and in-class observations suggest that students appreciated the large number of instructional hours of the course, perhaps because the structure and easy access to instructor assistance helped them complete a larger portion of their work than they otherwise might have. This observation is in line with a larger trend in higher education focusing on increasing instructional time to support students who might otherwise struggle. Some community colleges and universities have eliminated remedial courses in favor of co-requisite support. In this system, students with low scores on placement exams enroll in extra credits to increase instructional time while they take their required courses, rather than requiring them to first take a remedial course before enrolling in the required course [27]. The development and deployment of such courses is a promising area to promote collaboration and cross-institutional alignment between community colleges and universities [28]. However, increased instructional hours may prevent some students with full-time jobs from enrolling, so co-requisite support would need further refinement and research before being deployed to support engineering graphics students at a community college.

Based on our observations, nearly every student in the class, regardless of background, enjoyed learning how to create 3D CAD models. Some comments received on the survey include: "Overall a very fun and informative class" and "I can be kind of lazy at times and sometimes I put things off last minute, but I really liked this class, so I was able to do most of the assignments on time." CAD courses seem like a promising opportunity to get a wider cross-section of students interested in engineering and engineering technology programs, as long as they are supported with faculty attention, engaging activities, and adequate instructional time. 


\section{Conclusion}

This study focused on understanding barriers to student success in an engineering graphics course at a community college. Despite relatively low spatial visualization ability, students reported that finding time to complete out-of-class assignments was the largest barrier to their success in the course. Promising strategies to promote student confidence and learning include a focus on active learning, a high number of instructional hours, and recognition of students that may be at risk of dropping out of the course due to low spatial visualization ability. These findings provide guidance for helping to support diverse student bodies at other two- and fouryear institutions.

\section{References}

[1] C. Wilson, "Many Engineering Grads Start Out at Two-Year Colleges," ASEE Connections, October 3, 2019. [Online]. Available: https://ira.asee.org/many-engineering-grads-start-out-attwo-year-colleges/.

[2] G. Hawat, \& H. Regis, “Articulated Pre-Engineering Programs: How Community Colleges can be Effective Partners with Universities to Deliver Engineering Curriculum to Students," in Proceedings of the 2002 ASEE Annual Conference \& Exposition, Montreal, Canada, June 16-19, 2002.

[3] University of Arizona, Fast Facts. [Online]. Available: https://engineering.arizona.edu/about/

[4] Arizona State University, Enrollment by STEM Discipline - Metropolitan Campuses, January 2020. [Online]. Available: https://www.asu.edu/facts/\#/facts/enrollment/stem-metro-campus

[5] Maricopa Community College, Fast Facts, 2018. [Online]. Available:

https://cdn.maricopa.edu/data-reports/data/fast-facts/FastFacts_2018.pdf

[6] Pima Community College, Federal Reporting, 2018. [Online]. Available:

https://www.pima.edu/about-pima/reports/federal-reporting/index.html

[7] S. R. Porter and P. D. Umbach, "What challenges to success do community college students face?," Percontor, LLC, Raleigh, NC, 2019. Available:

https://www.risc.college/sites/default/files/2019-01/RISC_2019_report_natl.pdf

[8] Z. Prusak, "Learning environment in engineering technology with a high percentage of nontraditional students," in Proceedings of the 1999 ASEE Annual Conference \& Exposition, Charlotte, North Carolina, June 20-23, 1999.

[9] H. Budinoff \& S. McMains, "Relationships between Spatial Visualization Ability and Student Outcomes in a 3D Modeling Course," Engineering Design Graphics Journal, vol. 82, no. $2,2018$. 
[10] A. Hamlin, N. Boersma, and S. A. Sorby, "Do Spatial Abilities Impact the Learning of 3-D Solid Modeling Software?," in Proceedings of the 2006 ASEE Annual Conference, Chicago, IL, June 18-2, 2006.

[11] S. A. Sorby and N. Veurink, "Spatial skills among minority and international engineering students," in Proceedings of the 2012 ASEE Annual Conference, San Antonio, TX, June 10-13, 2012.

[12] J. L. Segil, J. F. Sullivan, B. A. Myers, D. T. Reamon, and M. H. Forbes, "Analysis of multi-modal spatial visualization workshop intervention across gender, nationality, and other engineering student demographics," in Proceedings of the 2016 Frontiers in Education Conference, Erie, PA, October 19-22, 2016.

[13] S. C. Levine, M. Vasilyeva, S. F. Lourenco, N.S Newcombe, and J. Huttenlocher, "Socioeconomic status modifies the sex difference in spatial skill," Psychological Science, vol. 16, no. 11, pp. 841-845, 2005.

[14] N.E. Study, "Long-term Impact of Improving Visualization Abilities of Minority Engineering and Technology Students," Proceedings of the 2011 ASEE Annual Conference \& Exposition, Vancouver, BC, June 26-29, 2011.

[15] O.O. Adebayo, E.J. Farrar, R. Evans, T.L. McCray, and T. Nathans-Kelly, "Empowering early mastery of spatial visualization skills in under represented minority engineering students," in Proceedings of the 2014 Frontiers in Education Conference, Madrid, Spain, October 22-25, 2014.

[16] J. Yue \& D.M. Chen, "Does CAD improve spatial visualization ability?," in Proceedings of the 2001 ASEE Annual Conference \& Exposition, Albuquerque, NM, June 24-27, 2001.

[17] S. A. Scribner and M. A. Anderson, "Novice Drafters' Spatial Visualization Development: Influence of Instructional Methods and Individual Learning Styles," Journal of Industrial Teacher Education, vol. 42, no. 2, pp. 38-60, 2005.

[18] K. P. Grimes and S. W. Daniel, “A Journey to Integrate Spatial Visualization into Community College Engineering and Technology Programs to Increase Student Diversity and Retention," in Proceedings of the 2017 ASEE Annual Conference \& Exposition, Columbus, OH, June 25-28, 2017.

[19] S. Metz, S.A. Sorby, and T. Jarosewich, "Spatial Skills Training Impacts Retention of Engineering Students - Does This Success Translate to Community College Students in Technical Education?," in Proceedings of the 2018 ASEE Annual Conference \& Exposition, Salt Lake City, UT, June 23-27, 2018.

[20] R. B. Guay, "Purdue Spatial Visualization Test: Rotations," West Lafayette: Purdue Research Foundation, 1977. 
[21] C. D. Denson \& D. P. Kelly, "Using Exploratory Factor Analysis to Build a Self-Efficacy Scale for Three-dimensional Modeling," Engineering Design Graphics Journal, vol. 82, no. 2, pp. 36-42, 2018.

[22] P. E. Connolly, "Spatial ability improvement and curriculum content," Engineering Design Graphics Journal, vol. 73, no. 1, 2009.

[23] S.A. Sorby, "Spatial Abilities and their Relationship to Computer Aided Design Instruction," in Proceedings of the 1999 ASEE Annual Conference \& Exposition, Charlotte, NC, June 20-23, 1999.

[24] J. Rodriguez, \& L. Genaro Rodriguez, "Comparison of Spatial Visualization Skills in Two Approaches to Entry-Level Graphic Courses," in Proceedings of the 2016 ASEE Annual Conference \& Exposition, New Orleans, LA, June 26-29, 2016.

[25] D. P. Kelly, "Measurements of self-efficacy in engineering graphics students: An examination of factors impacting student outcomes in an introductory engineering graphics course," Ph.D. dissertation, Technology Education, NC State University, Raleigh, NC, 2017.

[26] A. Enriquez, E. Dunmire, T. Rebold, N. Langhoff, \& T. Huang, "Strengthening Community College Engineering Programs through Alternative Learning Strategies: Developing an Online Engineering Graphics Course," in Proceedings of the 2017 ASEE Pacific Southwest Section Conference, Tempe, AZ, April 20-22, 2017.

[27] M. Zinshteyn, "As California community colleges gear up to teach less remedial math, one college shows how it can be done," EdSource, January 14, 2019. [Online]. Available: https://edsource.org/2019/as-california-community-colleges-gear-up-to-teach-less-remedialmath-one-college-shows-how-it-can-be-done/606490.

[28] L. C. Michas, M. Newberry, K.S. Uehling, \& A.L. Wolford, “A university-community college collaborative project to create co-requisite offerings and reduce remediation," Basic Writing e-Journal, vol. 14, no. 1, 2016. [Online]. Available: https://bwe.ccny.cuny.edu/Michas\%20et\%20al\%20.pdf 